\title{
Methylene Violet 3 RAX Dye as a New Reagent for the Determination of Nitrite in Cured Meats and Vegetables
}

\author{
Caroline O. da Rocha, João Flávio S. Petruci* and Arnaldo A. Cardoso \\ Departamento de Química Analítica, Universidade Estadual Paulista, \\ 14800-970 Araraquara-SP, Brazil
}

\begin{abstract}
In this contribution we propose, for the first time, the use of Methylene Violet 3 RAX dye for the detection and determination of nitrite in cured meats and vegetables. Quantification is based on the decrease in absorbance of the dye, which is proportional to the nitrite concentration. The proposed method presents linear response $(r>0.99)$ in the range from 1.8 to $9 \mu \mathrm{mol} \mathrm{L}^{-1}$ of nitrite, with a limit of detection of $0.14 \mu \mathrm{mol} \mathrm{L}{ }^{-1}$. Satisfactory accuracy with the official Association of Official Agricultural Chemists (AOAC) method was achieved, and the method was successfully applied to a wide range of cured meats and vegetables. The proposed method offers similar or superior performance to other optical methods used for the determination of nitrite in different matrices, with advantage in terms of reduction of chemical waste for each analysis, by minimizing amounts of reagents and products.
\end{abstract}

Keywords: nitrite, food analysis, cured meat, spectrophotometry, Methylene Violet 3RAX

\section{Introduction}

Nitrite was first recognized as an active component in the meat curing process at the end of the $19^{\text {th }}$ century. ${ }^{1}$ The presence of nitrite as an impurity in salt resulted in an attractive red color in cured meats such as bacon, ham, and sausages, and also enhanced the flavor. ${ }^{2}$ Moreover, nitrite is widely recognized to protect against Clostridium botulinum spores, assisting in the prevention of botulism. ${ }^{3}$ In addition to cured meats, nitrogen species occur naturally in vegetables consumed by humans. The nitrate ion is the main species present, because plants take up nitrogen from the soil in this form. Nitrates can be reduced to nitrites due to the action of bacteria. ${ }^{4}$

It is well known that once in the stomach, nitrite can react with secondary and tertiary amines to form $N$-nitroso compounds. ${ }^{5}$ Exposure to $\mathrm{N}$-nitrosamines shows a strong association with increased risk of gastric and esophageal cancer. ${ }^{6}$ In addition, nitrite ions oxidize iron atoms in the hemoglobin of red blood cells, forming methemoglobin, resulting in decreased oxygen carrying capacity of the blood and leading to the disease known as methemoglobinemia. ${ }^{7}$ High concentrations of nitrite in drinking water can be hazardous to health, especially in the case of infants and pregnant women. ${ }^{8}$

*e-mail: jfpetruci@gmail.com
Due to these toxic effects, agencies worldwide regulate the nitrite content of foods. An acceptable daily intake (ADI) for nitrite of $0-0.07 \mathrm{mg} \mathrm{kg}^{-1}$ body weight per day was established by the Joint FAO/WHO Expert Committee on Food Additives (JECFA). ${ }^{9}$ The Brazilian National Health Surveillance Agency (ANVISA), the federal regulatory agency responsible for the monitoring of food additives in Brazil, has established a concentration limit for nitrite in cured meats of $150 \mathrm{mg} \mathrm{kg}^{-1} .^{10}$

Analytical methods have been developed for the monitoring of nitrite in a wide range of matrices, including cured meats and vegetables. ${ }^{11}$ According to the official Association of Official Agricultural Chemists (AOAC) method reported in the literature, ${ }^{12}$ nitrite is determined by diazotization with sulfanilic acid and coupling with $N$-(1-naphthyl)-ethylenediamine dihydrochloride (NED) to form a highly colored azo dye $\left(\lambda_{\mathrm{MAX}}=540 \mathrm{~nm}\right)$. However, this method is time-consuming (total reaction time of 30 minutes) and requires two reaction steps. Moreover, for each single nitrite analysis is spent about of 87 and $27 \mu \mathrm{mol}$, for sulfanilic acid and NED, respectively. Different methods such as $\mathrm{KMnO}_{4}$ oxidation, $\mathrm{TiO}_{2}$-photocatalysis and photo-Fenton reaction have been employed for the degradation of wastes from this nitrite determination. ${ }^{13}$ Other analytical techniques reported in the literature include spectrophotometry, ${ }^{7,14-17}$ chromatography, ${ }^{18}$ capillary electrophoresis, ${ }^{1,5}$ chemiluminescence, ${ }^{15}$ and 
electrochemistry. ${ }^{6}$ Separation techniques (i.e., high performance liquid chromatography and capillary electrophoresis) provide suitable sensitivity, however they are usually time-consuming, laborious and require bulkiness and expensive instruments. Electrochemical methods generally suffer interference from the matrix, causing decrease of accuracy in the results.

Optical methods, based on absorbance or fluorescence, are most widely employed for nitrite determination. In the last decades, a large number of new compounds have been developed and applied for the detection of nitrite (Table 1). However, only a few methods have been developed and tested for the determination of nitrite in a wide range of foods and vegetables, and there is still a need for improved analytical methods suitable for quality control purposes.

The present work describes the use of Methylene Violet 3 RAX dye (3-amino-7-(diethylamino)5-phenylphenazinium chloride; MV 3 RAX; CAS Number: 4569-86-2) to determine nitrite in different matrices (cured meats and vegetables). The reaction between the dye and nitrite in an acid medium leads to a decrease in absorbance intensity that is inversely proportional to the concentration of nitrite in the solution. The method offers features including high sensitivity and selectivity, no use of toxic reagents, ease of operation, no interference from other components present in complex food matrices and using reduced quantity of reagent compared to the official AOAC method.

\section{Experimental}

\section{Materials and methods}

\section{Spectrophotometer}

Measurements of absorbance spectra and intensities employed a Hitachi Model U-2000 spectrophotometer fitted with a $10 \mathrm{~mm}$ quartz cuvette.

\section{Reagents and standard solutions}

All reagents were analytical grade and solutions were prepared using ultrapure water obtained from a Milli-Q system (Direct-Q ${ }^{\circledR}$ UV, Millipore, USA). Stock solutions of $4.5 \mathrm{mmol} \mathrm{L}^{-1}$ nitrite $\left(\mathrm{NaNO}_{2}\right.$, Merck, Darmstadt, Germany) and $4 \mathrm{mmol} \mathrm{L}^{-1}$ Methylene Violet 3 RAX (Sigma-Aldrich, St. Louis, USA) were prepared by dissolving appropriate amounts of the corresponding salts in water. A few drops of chloroform were added to the nitrite solution in order to inhibit bacterial growth. Working solutions were prepared daily by appropriate dilution of the stock solutions. The sulfanilic acid reagent was prepared by dissolving $600 \mathrm{mg}$ of sulfanilic acid in $50 \mathrm{~mL}$ of hot water. After cooling, a $20 \mathrm{~mL}$ volume of glacial acetic acid was added and the mixture was diluted to $100 \mathrm{~mL}$ with deionized water. The NED reagent was prepared by dissolving $20 \mathrm{mg}$ of $N$-(1-naphthyl)-ethylene diammonium dichloride in $20 \mathrm{~mL}$ of glacial acetic acid and diluting to $100 \mathrm{~mL}$ with deionized water.

Table 1. Comparison of the analytical performance of spectrophotometric nitrite determination

\begin{tabular}{|c|c|c|c|c|c|c|}
\hline Reagent & $\begin{array}{l}\text { Linearity / } \\
\left.(\mu \mathrm{mol} \mathrm{L})^{-1}\right)\end{array}$ & $\begin{array}{l}\text { Reaction } \\
\text { time / min }\end{array}$ & Matrix & Remark & Amount / $\mu \mathrm{mol}$ & Reference \\
\hline Safranine $\mathrm{T}$ & $0-1.8$ & 15 & water & $\begin{array}{l}\mathrm{pH} \text { dependent-time } \\
\text { consuming }\end{array}$ & 0.13 & 11 \\
\hline Sulfanilic acid + ethyl acetoacetate & $0.05-6.0$ & 10 & water and soil & $\mathrm{Fe}^{3+}$ interference & 48 & 7 \\
\hline$p$-Nitroaniline + 2-methyl-8- quinolinol & $2-28$ & 3 & water & $\begin{array}{l}\text { most cations and } \\
\text { anions interferes }\end{array}$ & 2 and 1.4 & 14 \\
\hline Luminol + ferricyanide & $8-100$ & 15 & food & few cured meat tested & 80 & 15 \\
\hline 1 Naphthol - sulphanilic acid & $2.5-100$ & 30 & meats & $\begin{array}{l}\text { high interference }+ \\
\text { time consuming }\end{array}$ & 56 and 12 & 16 \\
\hline Gallocyanine & $0.05-2.5$ & not found & food & $\begin{array}{l}\mathrm{pH} \text { and temperature } \\
\text { dependent }\end{array}$ & 4 & 17 \\
\hline Sulfunazo III & $0.1-6.5$ & not found & $\begin{array}{c}\text { food and } \\
\text { environmental }\end{array}$ & $\begin{array}{l}\text { temperature } \\
\text { dependent }\end{array}$ & 25 & 16 \\
\hline Sulfanilic Acid + NED & not found & 30 & food & $\begin{array}{l}\text { time consuming, } \\
\text { large amount of } \\
\text { reagents }\end{array}$ & 87 and 27 & 12 \\
\hline Methylene Violet 3 RAX & $1.8-9$ & 15 & meats and vegetables & & 45 & this work \\
\hline
\end{tabular}




\section{Sample preparation}

Meat products and vegetables were acquired from local supermarkets. Sausage, pork sausage, bologna, pepperoni, bacon, salami and ham samples were cut into pieces and homogenized manually using a mortar and pestle. Lettuce, spinach, and cabbage samples were first washed with deionized water. Approximately $20 \mathrm{~g}$ of the sample was homogenized using a high shear mixer (ULTRA-TURRAX Q252-K28, Quimis, Brazil) operated at $6000 \mathrm{rpm}$ for $3 \mathrm{~min}$ at room temperature $\left(23^{\circ} \mathrm{C}\right)$. A representative amount $(5.0 \mathrm{~g})$ of each homogenized sample was weighed out and placed in a Falcon tube. The sample was mixed with $30 \mathrm{~mL}$ of deionized water at $80^{\circ} \mathrm{C}$, then stirred for $2 \mathrm{~min}$ and heated at $80^{\circ} \mathrm{C}$ for $1 \mathrm{~h}$. After cooling to room temperature, the sample was filtered (Whatman 41, GE Healthcare Life Sciences, USA) and the volume was adjusted to $50.0 \mathrm{~mL}$ with deionized water. An aliquot of $2.0 \mathrm{~mL}$ was transferred to a volumetric flask and the volume was adjusted to $10.0 \mathrm{~mL}$ with deionized water.

\section{Design of experiments (DoE)}

The optimum conditions of the nitrite determination were obtained by using the design of experiments with a full factorial design (two-levels and two-factors) and surface response analysis. All the data were evaluated using Statistica 7.0 package software.

\section{Nitrite determination}

Aliquots of $11.25 \mathrm{~mL}$ of Methylene Violet $3 \mathrm{RAX}$ working solution $(45 \mu \mathrm{mol}), 2 \mathrm{~mL}$ of $\mathrm{HCl}\left(1 \mathrm{~mol} \mathrm{~L}^{-1}\right)$, and $830 \mu \mathrm{L}$ of sample extract solution were transferred to a $25.0 \mathrm{~mL}$ volumetric flask and the volume was completed with deionized water. The flask was kept at room temperature for $15 \mathrm{~min}$. The solution was then transferred to a cuvette and the absorbance $(\lambda=555 \mathrm{~nm})$ was measured against a blank.

Nitrite determination by the AOAC method (973.31)

A $5 \mathrm{~mL}$ aliquot of the sample extract solution was transferred to a $25.0 \mathrm{~mL}$ volumetric flask, followed by addition of $2.5 \mathrm{~mL}$ of sulfanilic acid reagent $(87 \mu \mathrm{mol})$. The mixture was homogenized and then left to stand for $15 \mathrm{~min}$ at room temperature, followed by addition of $2.5 \mathrm{~mL}$ of NED reagent $(27 \mu \mathrm{mol})$ and adjustment of the volume to $10.0 \mathrm{~mL}$. After $15 \mathrm{~min}$, the absorbance was measured at $540 \mathrm{~nm}$.

\section{Results and Discussion}

\section{Reaction between nitrite and Methylene Violet 3 RAX dye}

The structure of the Methylene Violet 3 RAX molecule includes an amino group that can react with nitrous acid (generated from reaction between nitrite and a strong acid), which results in the formation of diazonium salts (Figure 1). The absorbance spectrum of the dye solution showed maximum absorbance at $555 \mathrm{~nm}$ (Figure 2).

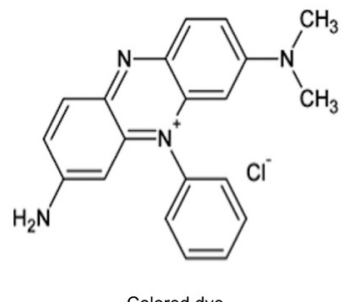

Colored dye

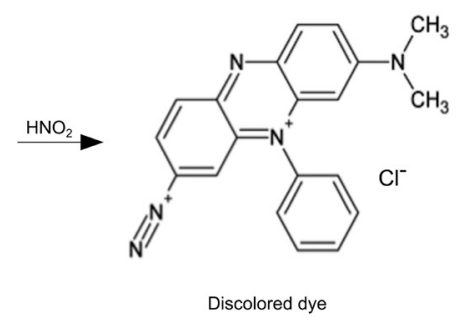

Discolored dye
Figure 1. Representation of the reaction between Methylene Violet 3 RAX dye and nitrite.

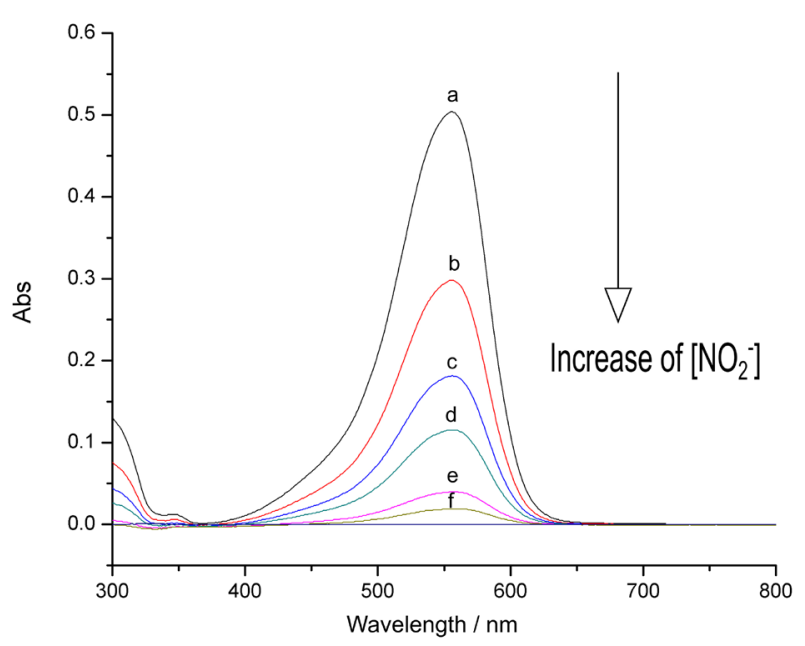

Figure 2. Absorbance spectra of Methylene Violet 3 RAX in aqueous solution with increasing nitrite concentration: (a) blank; (b) 1.8; (c) 3.6; (d) 5.4 ; (e) 7.2 ; (f) $9 \mu \mathrm{mol} \mathrm{L}{ }^{-1}$.

The reaction causes a decrease in absorbance intensity that is proportional to the amount of nitrite present in the solution. The analytical procedure was optimized in order to establish the best conditions for the reaction between the dye and nitrite, maximizing the analytical signal.

\section{Effect of reaction time}

The time necessary to the reactants to reaction equilibrium, thus producing a stable absorbance to be measured was evaluated. As shown in Figure 3, the absorbance decreased with reaction time, becoming 
stable after $15 \mathrm{~min}$ up to at least $60 \mathrm{~min}$. Therefore, in all subsequent experiments, the absorbance was measured after $15 \mathrm{~min}$.

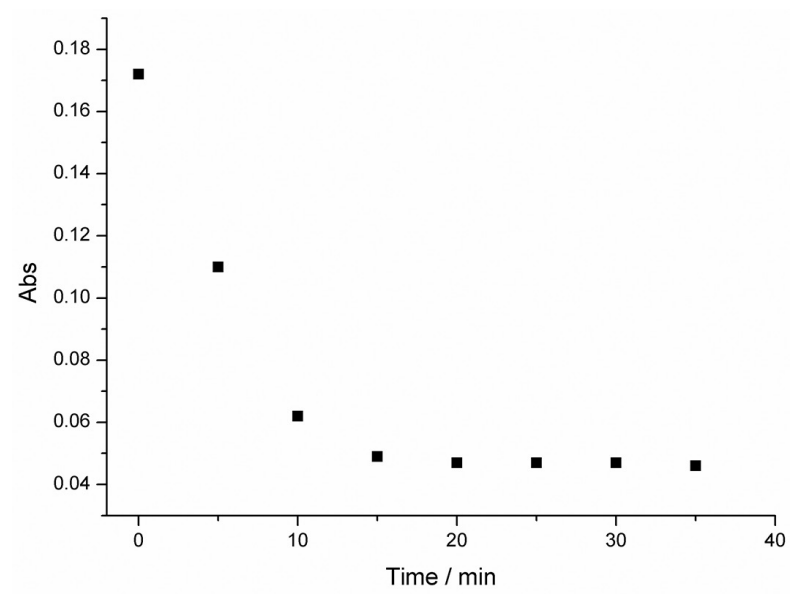

Figure 3. Change in absorbance as a function of time after nitrite addition.

\section{Optimization of experimental conditions}

Herein, a design of experiments was used to obtain the best conditions of the nitrite-dye reaction and, consequently, resulting in maximization of the analytical signal. Firstly, a full factorial design in two levels $(+1$ and -1 ) of two factors (concentration of Methylene Violet $3 \mathrm{RAX}$ and $\mathrm{HCl}$ ) was performed. Upper $(+1)$ and lower $(-1)$ levels were selected for each variable. In order to account for all possible combinations of factor levels, four independent experiments were randomly performed using two replicates, corresponding to a total of eight assays.

A Pareto chart is a graphical representation of the estimated effects of the variables. In this chart, the bars (variables) that exceed the significance line indicate a statistically significant influence on the result. In this case, the most significant effect was found for the Methylene Violet concentration (graph not shown). Despite having lower relative significance, an effect of the acid concentration was also observed.

Based on this evidence, these variables were studied in more detail using response surface analysis. The variables were analyzed at five levels, with one central point and the other levels located on a circumference of radius $\sqrt{ } 2$ from the central point (which was coded as zero). Table 2 lists the variables and levels used. The optimized conditions obtained using the response surface analysis experiments were established as $9 \mu \mathrm{mol} \mathrm{L}^{-1}$ of Methylene Violet $3 \mathrm{RAX}$ and $80.0 \mathrm{mmol} \mathrm{L}^{-1}$ of $\mathrm{HCl}$. In terms of volume, these corresponded to 11.25 and $2 \mathrm{~mL}$ of the dye and acid working solutions, respectively.
Table 2. Experimental variables considered in the surface analysis experiment for conditions optimization

\begin{tabular}{lcc}
\hline \multirow{2}{*}{ Level } & \multicolumn{2}{c}{ Variable } \\
\cline { 2 - 3 } & $\mathrm{MV} 3 \mathrm{RAX} /\left(\mu \mathrm{mol} \mathrm{L}^{-1}\right)$ & $\mathrm{HCl} /\left(\mathrm{mmol} \mathrm{L}^{-1}\right)$ \\
\hline$-\sqrt{ } 2$ & 4.00 & 20 \\
-1 & 5.16 & 30 \\
0 & 8.00 & 60 \\
1 & 10.8 & 90 \\
$\sqrt{2}$ & 12.0 & 100 \\
\hline
\end{tabular}

MV 3RAX = Methylene Violet 3 RAX.

\section{Evaluation of interferences}

Investigation was made of possible interferences in the analytical signal caused by the presence of ions other than nitrite. The influences of $\mathrm{SO}_{4}{ }^{2-}, \mathrm{NO}_{3}{ }^{-}, \mathrm{CO}_{3}{ }^{2-}, \mathrm{Cl}^{-}$, $\mathrm{PO}_{4}^{3-}, \mathrm{SCN}^{-}, \mathrm{C}_{2} \mathrm{O}_{6}^{-}, \mathrm{Cu}^{2+}, \mathrm{Fe}^{3+}, \mathrm{Na}^{+}, \mathrm{K}^{+}$and $\mathrm{Mg}^{2+}$ on the determination of $5 \mu \mathrm{mol} \mathrm{L}{ }^{-1}$ of nitrite were investigated using different proportions of the interfering ion (1:1, 1:5, and 1:10). Interference was considered whether the foreign ions produced deviation in the analytical signal superior than $2 \%$. The results showed that the ions evaluated did not interfere in the determination of nitrite based on the reaction with Methylene Violet 3 RAX.

\section{Analytical figures of merit}

For quantitative purposes, a calibration function was obtained from a plot of the absorbance of the dye solution at $555 \mathrm{~nm}$ against nitrite concentrations in the range from 1.8 to $9.0 \mu \mathrm{mol} \mathrm{L} \mathrm{L}^{-1}$. For each concentration, the mean value of three replicate measurements was calculated. The proposed method showed excellent linearity over this concentration range. The calculated limits of detection (LOD) and quantification (LOQ), considered as three and ten times the standard deviation of the blank signal, were 0.14 and $0.43 \mu \mathrm{mol} \mathrm{L}^{-1}$, respectively.

The accuracy of the method was evaluated in terms of recovery, using sausage as an example food matrix. Samples were spiked with known amounts of nitrite and then submitted to the extraction procedure. Recoveries were calculated by comparing the absorbances obtained for samples spiked before and after the extraction. The mean recoveries revealed excellent accuracy, with values ranging from 93 to $97 \%$. All the analytical results are summarized in Table 3.

\section{Application using real samples}

Samples of sausage, pork sausage, bologna, pepperoni, bacon, salami, ham, lettuce, spinach, and cabbage were 
Table 3. Analytical performance of the proposed method for nitrite determination

\begin{tabular}{lc}
\hline Parameter & Value \\
\hline Limit of detection $(\mathrm{LOD}) /\left(\mu \mathrm{mol} \mathrm{L}{ }^{-1}\right)$ & 0.14 \\
Limit of quantification $(\mathrm{LOQ}) /\left(\mu \mathrm{mol} \mathrm{L}^{-1}\right)$ & 0.43 \\
Correlation coefficient & 0.996 \\
Linear range / $\left(\mu \mathrm{mol} \mathrm{L}{ }^{-1}\right)$ & $1.8-9.0$ \\
Regression equation & $\mathrm{A}=0.286-1.28 \times 10^{4}\left[\mathrm{NO}_{2}^{-}\right]$ \\
Recovery (low level) / \% & $96.9 \pm 0.01$ \\
Recovery (medium level) / \% & $94.9 \pm 0.02$ \\
Recovery (high level) / \% & $93.9 \pm 0.02$ \\
Repeatability $(\mathrm{n}=5) / \%$ & 1.9 \\
Instrumental precision $(\mathrm{n}=10) / \%$ & 0.03 \\
\hline
\end{tabular}

analyzed by the proposed methodology and compared to the standard method for nitrite determination. For each sort of sample, a mean of three replicates was used to concentration calculation. The results (Table 4) obtained using Methylene Violet 3 RAX were consistent with those obtained by the AOAC method, in terms of both precision and accuracy, as confirmed by F-test and $t$-test calculations (all values fell below the critical values for $t$ of 2.98, and for $\mathrm{F}$ of 19.0, at $p=0.05$ ). Therefore, the results obtained by the new and the official method are no statistical distinguishable at the $95 \%$ confidence level. It suggests that the proposed approach might be employed to monitoring of nitrite in cured meat and vegetable samples with suitable accuracy.

Table 4. Comparison of the proposed and AOAC method ${ }^{12}$ for the determination of nitrite in meat and vegetables

\begin{tabular}{lcc}
\hline Matrix & $\begin{array}{c}\text { Proposed method / } \\
\left(\mathrm{mg} \mathrm{kg}^{-1}\right)\end{array}$ & $\begin{array}{c}\text { AOAC method / } \\
\left(\mathrm{mg} \mathrm{kg}^{-1}\right)\end{array}$ \\
\hline Sausage & $133 \pm 3$ & $127 \pm 2$ \\
Ham & $<\mathrm{LOD}$ & $<\mathrm{LOD}$ \\
Bacon & $15 \pm 7$ & $14 \pm 8$ \\
Salami & $<\mathrm{LOD}$ & $<\mathrm{LOD}$ \\
Pork sausage & $<\mathrm{LOD}$ & $<\mathrm{LOD}$ \\
Pepperoni & $36 \pm 10$ & $38 \pm 10$ \\
Bologna & $<$ LOD & $<$ LOD \\
Cabbage & $<$ LOD & $<$ LOD \\
Spinach & $36 \pm 5$ & $38 \pm 6$ \\
Lettuce & $<$ LOD & $<$ LOD \\
\hline
\end{tabular}

LOD = limit of detection; AOAC $=$ Association of Official Agricultural Chemists.

\section{Conclusions}

In this study, we propose the use of a new reactant for the sensitive and selective spectrophotometric determination of nitrite in cured meats and vegetables. The proposed method is based on the reaction between Methylene Violet 3 RAX and nitrite in aqueous media, resulting in a decrease in the absorbance measured at $555 \mathrm{~nm}$ that is proportional to the nitrite concentration. The experimental conditions were optimized using factorial design, enabling a limit of detection of $0.14 \mu \mathrm{mol} \mathrm{L}^{-1}$ to be achieved. Compared to other methods described in the literature, this new method offers similar or superior performance in terms of reaction time, sensitivity, and range of food applications. We emphasize that this nitrite determination method uses about one-third mol of organic molecules than the Griess method. This means that the generation of waste is much smaller and consequently less potential to cause pollution.

\section{Acknowledgments}

The authors thank FAPESP (São Paulo Research Foundation) (No. 2013/22995-4), CAPES (Coordination for the Improvement of High Level Personnel), and CNPq (National Council for Scientific and Technological Development) for financial support.

\section{References}

1. Pereira, E. A.; Petruci, J. F. S.; Cardoso, A. A.; Food Anal. Methods 2012, 5, 637.

2. Heaton, K. M.; Cornforth, D. P.; Moiseev, I. V.; Egbert, W. R.; Carpenter, C. E. M.; Meat Sci. 2000, 55, 321.

3. Stalikas, C. D.; Konidari, C. N.; Nanos, C. G.; J. Chromatogr. A 2003, 1002, 237.

4. Huang, K.-J.; Wang, H.; Guo, Y.-H.; Fan, R.-L; Zhang, H.-S.; Talanta 2006, 69, 73.

5. Merusi, C.; Corradini, C.; Cavazza, A.; Borromei, C.; Salvadeo, P.; Food Chem. 2010, 120, 615.

6. Yilmaz, Ü. T.; Somer, G.; J. Electroanal. Chem. 2008, 624, 59.

7. Sreekumar, N. V.; Narayana, B.; Hegde, P.; Manjunatha, B. R.; Sarojini, B. K.; Microchem. J. 2003, 74, 27.

8. Butt, S.; Talanta 2001, 55, 789.

9. Jimidar, M.; Hartmann, C.; Cousement, N.; Massart, D. L.; J. Chromatogr. A 1995, 706, 479.

10. http://portal.anvisa.gov.br/documents/33916/391619/Portaria $\% 2 \mathrm{Bn} \% 25 \mathrm{C} 2 \% 25 \mathrm{BA} \% 2 \mathrm{~B} 1004 \% 252 \mathrm{C} \% 2 \mathrm{Bde} \% 2 \mathrm{~B} 11 \% 2 \mathrm{Bde} \%$ 2Bdezembro\%2Bde\%2B1998.pdf/41e1bc8f-b276-4022-9afbff0bb3c12c0c accessed in January 2017.

11. Viñas, P.; Cordoba, M. H.; Pedreno, C. S.; Int. J. Environ. Anal. Chem. 1987, 32, 279.

12. Association of Official Analytical Chemists (AOAC); Methods of Analysis. 973.31 Nitrites in Cured Meat. Colorimetric Method; AOAC: Rockville, 1996; Association of Official 
Analytical Chemists (AOAC); Methods of Analysis. 993.03 Nitrate in Baby Foods. Spectrophotometric Method; AOAC: Rockville, 1993.

13. Chowdhuri, A.; Gupta, V.; Sreenivas, K.; Sens. Actuators, B 2003, 93, 572.

14. Nair, J.; Gupta, V. K.; Anal. Chim. Acta 1979, 111, 311.

15. He, D.; Zhang, Z.; Huang, Y.; Hu, Y.; Food Chem. 2007, 101, 667.
16. Nouroozi, S.; Mirshafian, R.; Talanta 2009, 79, 1149.

17. Ensa, A. A.; Kazemzadeh, A.; Anal. Chim. Acta 1999, 382, 15.

18. Ferreira, I. M. P. L. V. O.; Silva, S.; Talanta 2008, 74, 1598.

Submitted: December 9, 2016

Published online: January 24, 2017 